\title{
Perbandingan Metode Holt Exponential Smoothing dan Winter Exponential Smoothing Untuk Peramalan Penjualan Souvenir
}

\author{
Ruli Utami ${ }^{1}$, Suryo Atmojo ${ }^{2}$ \\ ${ }^{1}$ Institut Teknologi Adi Tama Surabaya \\ ${ }^{2}$ Universitas Wijaya Putra \\ ${ }^{1}$ ruli.utami@itats.ac.id,2suryoatm@gmail.com
}

\begin{abstract}
ABSTRAK.UD. Fajar Jaya merupakan unit usaha dagang yang bergerak pada bidang penyediaan souvenir. Dalam penjualan souvenir, seringkali UD. Fajar Jaya mengalami kekosongan stok souvenir ketika pesanan membludak di waktuwaktu tertentu. Hal ini terjadi karena tidak terdapat analisa dan strategi manajemen stok (tidak dapat memprediksi berapa jumlah optimal souvenir yang harus di sediakan) yang di lakukan oleh eksekutif UD. Fajar Jaya. Untuk mengatasi hal tersebut di atas, maka penulis mengusulkan untuk melakukan peramalan terhadap tingkat penjualan souvenir dengan menggunakan metode Holt dan Winter yang ada pada pengembangan metode Exponential Smoothing (ES). Dari penerapan kedua metode tersebut, kemudian dibuat perbandingan efektifitas metode yang di ukur melalui akurasi data aktual dan hasil peramalan dengan cara mengetahui tingkat kesalahan peramalan. Dari hasil penelitian diperoleh hasil peramalan untuk metode Holt Exponential Smoothing bulan Juli tahun 2017 adalah sebesar 599 item yang mungkin akan terjual dengan tingkat kesalahan peramalan MAPE sebesar 20.5\%. Sedangkan untuk peramalan menggunakan metode Winter Exponential Smoothing pada bulan Juli tahun 2017 adalah sebesar 549.6 item yang mungkin akan terjual dengan tingkat kesalahan MAPE sebesar 12.6\%.
\end{abstract}

Kata Kunci: Exponential Smoothing, Holt, Peramalan, Winter

ABSTRACT.UD. Fajar Jaya is a trading business unit engaged in the supply of souvenirs. In sales of souvenirs, often UD. Fajar Jaya experienced a vacuum of souvenir stock when order overload at certain times. This happens because there is no analysis and stock management strategy (cannot predict how optimal the souvenirs should be provided) which is done by UD executives. Fajar Jaya. To overcome the above, the authors propose to forecast the level of sales of souvenirs using Holt and Winter methods that exist in the development of Exponential Smoothing (ES) method. From the application of these two methods, then made a comparison of the effectiveness of the measured method through the accuracy of actual data and forecasting results by knowing the level of forecasting errors. From the research results obtained forecasting results for Holt Double Exponential Smoothing method in July of 2017 is 599 items that may be sold with MAPE forecasting error rate of 20.5\%. As for forecasting using Winter Exponential Smoothing method in July of 2017 is 549.6 items that may be sold with MAPE error rate of $12.6 \%$.

Keywords: Exponential Smoothing, Forecasting, Holt, Winter

\section{PENDAHULUAN}

Penjualan dan pelayanan terhadap konsumen merupakan aktifitas puncak dari sebuah bisnis komersial, termasuk juga pada Usaha Dagang (UD) Fajar Jaya yang bergerak dalam penjualan souvenir pernikahan, ulang tahun, seserahan, dan event-event lain. Dalam penjualan souvenir, seringkali UD. Fajar Jaya mengalami kekosongan stok souvenir ketika pesanan membludak di waktu-waktu tertentu. Hal ini terjadi karena tidak terdapat analisa dan strategi manajemen stok (tidak dapat memprediksi berapa jumlah optimal souvenir yang harus di sediakan) yang di lakukan oleh eksekutif UD. Fajar Jaya. Seringnya kekosongan stok souvenir ini menyebabkan pelayanan kepada konsumen kurang maksimal, apalagi pada saat-saat tertentu penjualan souvenir (contoh: souvenir gelas) melonjak drastis dari jumlah penjualan ratarata. Untuk dapat membuat analisa peramalan stok souvenir, maka akan dibuat perhitungan peramalan dengan membandingkan dua metode yaitu metode yang dikemukakan oleh Holt dan Winter yang ada pada pengembangan metode Exponential Smoothing (ES).

Metode peramalan merupakan metode yang digunakan untuk mengestimasikan obyek yang dimaksudkan, dalam hal ini adalah peramalan terhadap tingkat penjualan souvenir. Peramalan ini di lakukan dengan terlebih dahulu menganalisis trend data penjualan periode yang lalu (Lieberty et al, 2015). Dari data yang telah tersebut, penulis mengusulkan penerapan dua metode yaitu metode yang dikemukakan oleh Holt dan Winter yang ada pada pengembangan metode Exponential Smoothing (ES). Dari penerapan kedua metode tersebut, kemudian akan dibuat perbandingan efektifitas metode yang di ukur melalui akurasi data 
aktual dan hasil peramalan dengan cara mengetahui tingkat kesalahan peramalan. Metode perhitungan kesalahan peramalan yang digunakan adalah Mean Absolute Percentage Error (MAPE).Dari pengolahan data peramalan ini, diharapkan akan menghasilkan peramalan dengan nilai kesalahan yang paling kecil, sehingga pihak UD. Fajar Jaya dapat mengestimasikan persediaan souvenir yang dijual, sehingga tidak terjadi kekurangan atau penumpukan stok souvenir.

Mengacu pada penelitian yang telah dilakukan oleh Andini et al pada tahun 2016terhadap peramalan penjualan Alat Tulis Kantor (ATK) menggunakan metode Exponential Smoothing (ES) yang dikemukakan oleh Holt. Hasil penelitian pada data yang mengandung pola musiman ini menghasilkan nilai kesalahan sebesar $12.4 \%$. melihat pola data yang sama pada penelitian yang akan diangkat (pola musiman), maka dalam peneliti mencoba untuk membuat perbandingan dua metode dengan pola data yang sama.

\section{Peramalan}

Peramalan merupakan sebuah langkah dapat di tempuh untuk memperoleh prediksi terhadap kejadian di masa mendatang (Agustine et al, 2017). Dengan menerapkan peramalan, sebuah perusahaan dapat membuat estimasi berapa stok optimal produk yang harus disediakan untuk melayani kebutuhan pelanggan. Sehingga perusahaan dapat membuat sebuah strategi pemasaran untuk menghasilkan keuntungan maksimal (Andini, 2016). Sebelum dilakukan peramalan, maka terlebih dahulu harus di lakukan pengkajian pada data periode yang lalu. Dari data periode yang telah lalu, kemudian di analisa tren data tersebut sehingga dapat dilakukan pemilihan metode yang tepat. Langkah terakhir yang harus dilakukan adalah dengan memproyeksikan data tersebut, sehingga di peroleh data peramalan dengan mempertimbangkan nilai kesalahan terkecil.

Ada banyak metode yang dapat diterapkan dalam pengolahan data peramalan, salah satunya adalah Exponential Smoothing. Dalam penelitian ini akan di bahas penggunaan dua metode Exponential Smoothing, yaitu Holt Double Exponential Smoothing dan Winter Exponential Smoothing (Triple Exponential Smoothing Multiplicative) (Supriatna et al, 2017).

\section{Holt Double Exponential Smoothing}

Dalam meramalkan sebuah data, Exponential Smoothing akan menaksirkan berapa nilai rata-rata data periode yang digunakan untuk mendapatkan nilai peramalan pada periode selanjutnya (Utama et al, 2016). Holt Double Exponential Smoothing merupakan model yang di kemukakan oleh Holt, model ini biasanya digunakan pada data dengan trend linier yang tidak dipengaruhi oleh musim (Mansyur et al, 2015). Dalam melakukan pemulusan, maka digunakan parameter yang berbeda dari data aktual. Setelah dilakukan pemulusan (smoothing) kemudian akan dilakukan estimasi trend. Model Holt menggunakan dua parameter yaitu $\alpha$ dan $\beta$ (Hartono, 2012). Rumus yang gunakan dalam Holt Double Exponential Smoothing adalah sebagai berikut:

$$
\begin{aligned}
& A_{t}=\alpha Y_{t}+(1-\alpha)\left(A_{t-1}+T_{t-1}\right) \\
& T_{t}=\beta\left(A_{t}-A_{t-1}\right)+(1-\beta) T_{t-1}
\end{aligned}
$$

Untuk menghitung nilai pemulusan maka kita akan membutuhkan nilai yang pertama $\left(\mathrm{A}_{1}\right)$, namun karena nilai $A_{1}$ pada $t_{1}$ tidak diketahui maka nilai $A_{1}$ dapat digunakan nilai data aktual yang pertama yaitu $Y_{1}$. Sehingga nilai $A_{1}=Y_{1}$. Sedangkan untuk menghitung estimasi trend, $T_{1}$ dapat diasumsikan bahwa $T_{1}=Y_{2}-$ $\mathrm{Y}_{1}$. Sedangkan untuk menghitung nilai peramalan periode yang akan dating, digunakan rumus:

$$
\hat{Y}_{t+p}=A_{t}+T_{t} p
$$

Dengan ketentuan:

$\mathrm{A}_{\mathrm{t}} \quad$ : Nilai pemulusan $\mathrm{ke}-\mathrm{t}$

$\alpha \quad$ : Parameter pemulusan untuk data $(0 \leq \alpha \leq 1)$

$\beta \quad$ : Parameter pemulusan untuk estimasi trend $(0 \leq \beta \leq 1)$

$\mathrm{Y}_{\mathrm{t}} \quad$ : Data Aktual ke $-\mathrm{t}$

$\mathrm{T}_{\mathrm{t}} \quad$ : Estimasi trend $\mathrm{ke}-\mathrm{t}$

$\mathrm{p}$ : Jumlah periode yang akan diramalkan

$\hat{Y}_{t+p} \quad$ : Nilai data ramalan 


\section{Winter Exponential Smoothing (Triple Exponential Smoothing Multiplicative)}

Model Winter Exponential Smoothing (Triple Exponential Smoothing Multiplicative)ini digunakan untuk meramalkan data dengan pola musiman. Berbeda dengan model Holt Double Exponential Smoothing, model Triple Exponential Smoothing Multiplicative menggunakan tiga parameter untuk mencapai nilai peramalan yaitu $\alpha, \beta$, dan $\mu$. Langkah untuk melakukan peramalan terdiri dari 3 bagian yaitu proses pemulusan $\left(\mathrm{A}_{\mathrm{t}}\right)$, proses estimasi trend $\left(\mathrm{T}_{\mathrm{t}}\right)$, dan proses estimasi musiman $\left(\hat{Y}_{t+p}\right)$ (Siregar et al, 2017). Rumus yang digunakan untuk menghitung pemulusan adalah sebagai berikut:

$$
\begin{aligned}
& A_{t}=\alpha \frac{Y_{t}}{S_{t-L}}+(1-\alpha)\left(A_{t-1}+T_{t-1}\right) \\
& T_{t}=\beta\left(A_{t}-A_{t-1}\right)+(1-\beta) T_{t-1} \\
& S_{t}=\mu \frac{Y_{t}}{A_{t}}+(1-\mu) S_{t-L}
\end{aligned}
$$

Sama halnya dengan model Holt Double Exponential Smoothing, nilai $\mathrm{A}_{1}$ dapat diasumsikan sama dengan nilai data aktual yang pertama yaitu $\mathrm{Y}_{1}$. Sedangkan nilai $\mathrm{T}_{1}$ dapat diasumsikan bernilai 0 (karena nilai trend yang diperoleh dari periode yang lalu tidak ada). Dan nilai estimasi musiman awal $\left(\mathrm{S}_{1}\right)$ diasumsikan dengan nilai 1(menghilangkan pengaruh musiman pada data aktual) (Mahkya et al, 2014). Rumus untuk menentukan nilai ramalannya adalah sebagai berikut:

$$
\hat{Y}_{t+p}=\left(A_{t}+T_{t} p\right) S_{t-L+p}
$$

Dengan ketentuan:

$\mu \quad$ : Parameter pemulusan untuk estimasi musiman $(0 \leq \mu \leq 1)$

$\mathrm{S}_{\mathrm{t}} \quad$ : Estimasi musiman $\mathrm{ke}-\mathrm{t}$

L : Panjangnya musim

\section{Pengukuran Hasil Peramalan}

Dalam penelitian ini, penulis menggunakan ukuran penilai akurasi hasil peramalan Mean Absolute Percentage Error (MAPE).

MAPE dapat dihitung dari nilai mutlak hasil pengurangan data aktual dan data peramalan yang kemudian di bagi dengan data aktual (Hartono, 2012). Rumus untuk perhitungan MAPE adalah sebagai berikut:

$$
\text { MAPE }=\left(\frac{100}{n}\right) \sum_{t=1}^{n}\left|\frac{Y_{t}-\hat{Y}_{t}}{Y_{t}}\right|
$$

\section{METODE}

Metode yang digunakan penulis dalam penelitian ini adalah dua metode yaitu Holt Double Exponential Smoothing dan Winter Exponential Smoothing atau sering disebut dengan Triple Exponential Smoothing Multiplicative. Kedua metode diimplementasikan dan kemudian dibandingkan untuk mendapatkan hasil metode mana yang paling akurat dalam meramalkan penjualan pada periode yang akan datang, akurasi hasil ini di peroleh dari perhitungan tingkat kesalahan dengan menggunakan Mean Absolute Percentage Error (MAPE). Sehingga akan diperoleh data yang paling akurat untuk peramalan yang akan dating.

Sedangkan untuk data yang digunakan sebagai studi kasus peramalan adalah data penjualan souvenir pada UD. Fajar Jaya yang berlokasi di Surabaya Barat dengan rincian periode satu tahun terakhir (2016-2017). Data ini diperoleh melalui survey terhadap pemilik usaha secara langsung, adapun data yang dikumpulkan adalah terkait jumlah penjualan masing-masing item souvenir. Namun demikian, hanya satu item saja yang dijadikan sampel dalam perhitungan peramalan yaitu penjualan item souvenir gelas. Adapun langkah-langkah dalam penelitian dapat di lihat pada gambar 1. 


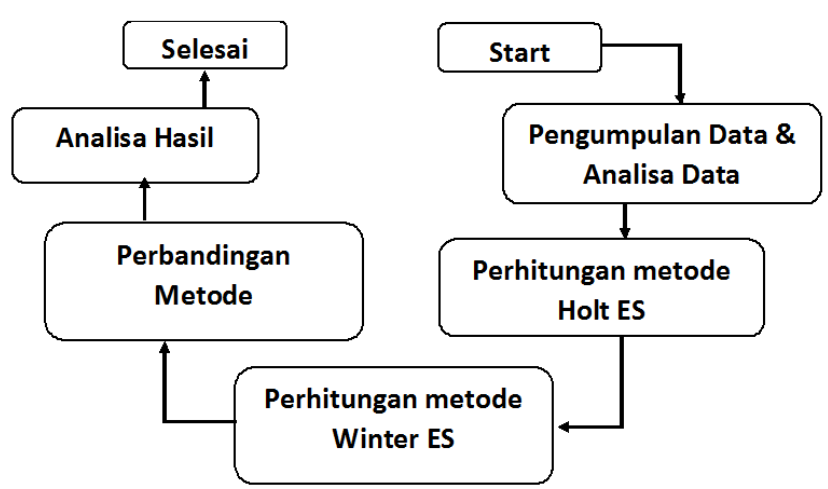

Gambar 1. Metode Penelitian

\section{HASIL DAN PEMBAHASAN}

Data yang di analisa dalam penelitian ini adalah data kuantitatif penjualan souvenir gelas dalam kurun waktu satu tahun (tahun 2016-2017). Sebagai awal langkah penelitian, penyajian data dipresentasikan dalam bentuk grafik untuk diketahui pola trend dari data tersebut. Data tersaji pada gambar2 berikut.

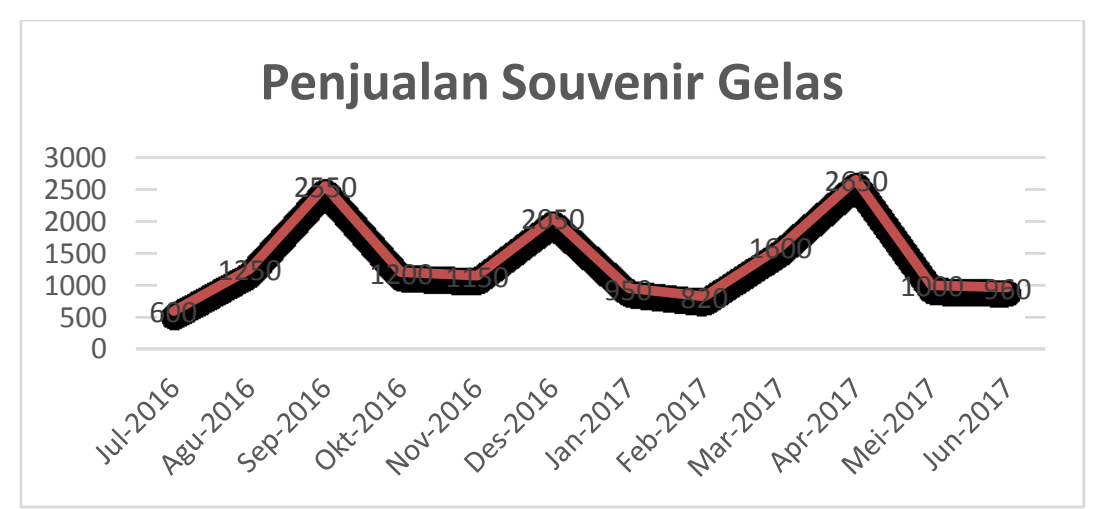

Gambar 2. Pola Data Aktual

Dari data tersebut di atas, kemudian akan di olah menggunakan dua metode yang telah direkomendasikan oleh penulis. Dalam pengolahan data peramalan, penulis menggunakan nilai $\alpha$ dan $\beta$ yang sama pada kedua metode dengan rincian nilai $\alpha=0.8$, nilai $\beta=0.6$ dan nilai $\mu=0.3$.

\section{Peramalan Menggunakan Metode Holt Double Exponential Smoothing}

Dalam metode ini digunakan dua parameter atau konstanta yaitu $\alpha$ dan $\beta$. Parameter $\alpha$ digunakan pada pemulusan dengan menggunakan persamaan 1, kemudian dilanjutkan dengan penentuan estimasi trend dengan persamaan 2. Dan langkah terakhir adalah menghitung nilai peramalan dengan menggunakan persamaan 3 .

Contoh perhitungan nilai pemulusan ke -2 :

$\mathrm{A}_{2}=(0.8 * 1250)+(1-0.8)(600+650)$

$\mathrm{A}_{2}=1250$

Contoh perhitungan Estimasi Tren ke -2 :

$\mathrm{T}_{2}=0.6(1250-600)+(1-0.6) 650$

$\mathrm{T}_{\mathrm{t}}=650$

Contoh perhitungan nilai peramalan $\mathrm{ke}-2$ :

$\hat{Y}_{t+p}=A_{t}+T_{t} p$

$\hat{Y}_{2}=1250+650$

$\widehat{Y}_{2}=1900$

Hasil dari perhitungan seperti tertera pada tabel 1 di bawah ini. 
Tabel 1. Hasil Peramalan Metode Holt Double Exponential Smoothing

\begin{tabular}{|c|c|c|c|}
\hline Periode & Data Aktual & Nilai ramalan & МАРЕ \\
\hline Jul-2016 & 600 & & \\
\hline Agu-2016 & 1250 & 1900 & 52 \\
\hline Sep-2016 & 2550 & 3382 & 32.6 \\
\hline Okt-2016 & 1200 & 1551 & 29.3 \\
\hline Nov-2016 & 1150 & 952 & 17.2 \\
\hline Des-2016 & 2050 & 2079 & 1.4 \\
\hline Jan-2017 & 950 & 883 & 7.1 \\
\hline Feb-2017 & 820 & 509 & 37.9 \\
\hline Mar-2017 & 1600 & 1582 & 1.1 \\
\hline Apr-2017 & 2650 & 3149 & 18.8 \\
\hline Mei-2017 & 1000 & 1111 & 11.1 \\
\hline Jun-2017 & 960 & 599 & 37.6 \\
\hline \multirow[t]{2}{*}{ Jul-2017 } & \multirow{2}{*}{\multicolumn{2}{|c|}{$\begin{array}{c}599 \\
\text { Tingkat Kesalahan }\end{array}$}} & \\
\hline & & & 20.5 \\
\hline
\end{tabular}

Hasil peramalan menggunakan metode Holt Double Exponential Smoothing menunjukkan hasil ramalan untuk bulan Juli tahun 2017 adalah 599 item yang terjual. Sedangkan tingkat kesalahan MAPE sebesar $20.5 \%$. Hal ini menunjukkan bahwa tingkat akurasi masih belum terlalu besar. Hasil perbandingan antara data aktual dan data hasil peramalan menggunakan metode Holt Double Exponential Smoothing dapat dilihat pada gambar 3 .

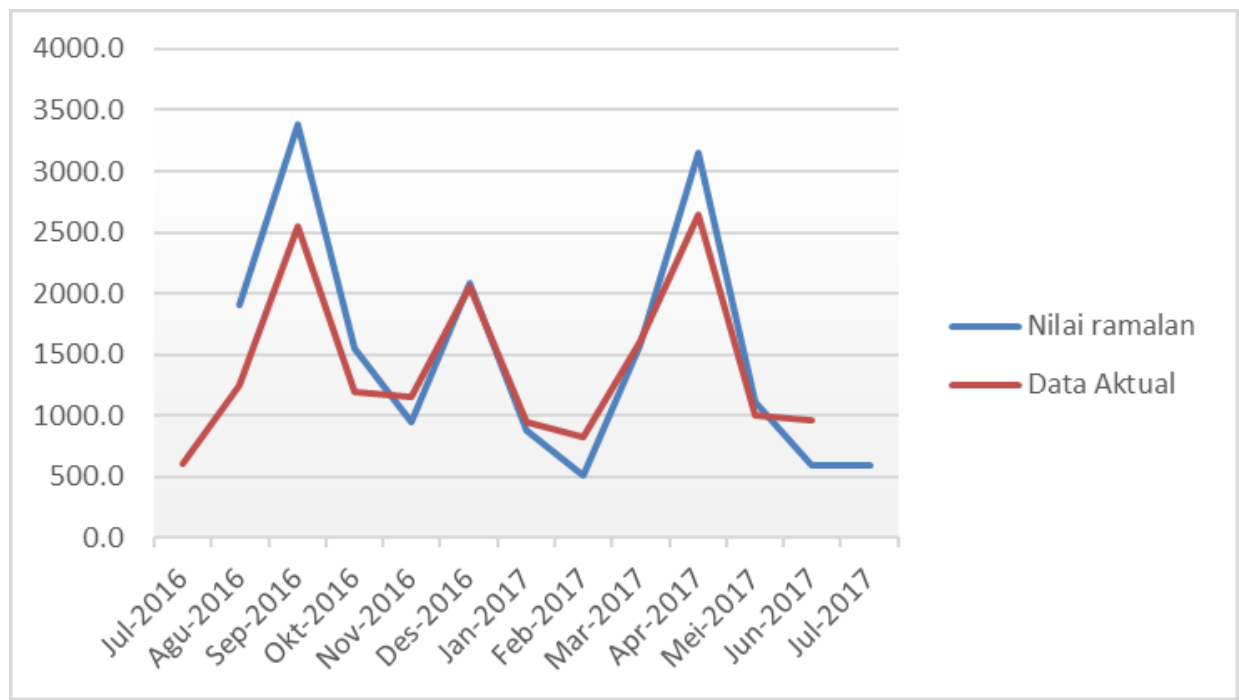

Gambar 3. Grafik Hasil Peramalan Metode Holt Double Exponential Smoothing

2. Peramalan Menggunakan Metode Winter Exponential Smoothing (Triple Exponential Smoothing Multiplicative)

Tabel 2. Hasil Peramalan Metode Winter Exponential Smoothing

\begin{tabular}{cccr}
\hline Periode & Data Aktual & Hasil Ramalan & MAPE \\
\hline Jul-2016 & 600 & & \\
Agu-2016 & 1250 & & \\
Sep-2016 & 2550 & & \\
Okt-2016 & 1200 & 1602.2 & 33.51 \\
Nov-2016 & 1150 & 1058.0 & 8 \\
Des-2016 & 2050 & 2152.2 & 4.98
\end{tabular}




\begin{tabular}{cccr}
\hline Periode & Data Aktual & Hasil Ramalan & MAPE \\
\hline \hline Jan-2017 & 950 & 818.1 & 13.89 \\
Feb-2017 & 820 & 521.5 & 36.41 \\
Mar-2017 & 1600 & 1663.6 & 3.98 \\
Apr-2017 & 2650 & 2789.6 & 5.27 \\
Mei-2017 & 1000 & 1123.4 & 12.34 \\
Jun-2017 & 960 & 649.0 & 32.39 \\
Jul-2017 & \multicolumn{3}{c}{ Tingkat Kesalahan } \\
\multicolumn{3}{c}{} \\
\end{tabular}

Sedangkan untuk hasil pengolahan data peramalan menggunakan metode Winter Exponential Smoothing dengan nilai $\mu=0.3$ dan panjang musim $\mathrm{L}=3$ menghasilkan nilai peramalan untuk bulan Juli tahun 2017 adalah sebesar 549.6 item yang terjual, dengan perhitungan nilai MAPE sebesar 12.6\%.

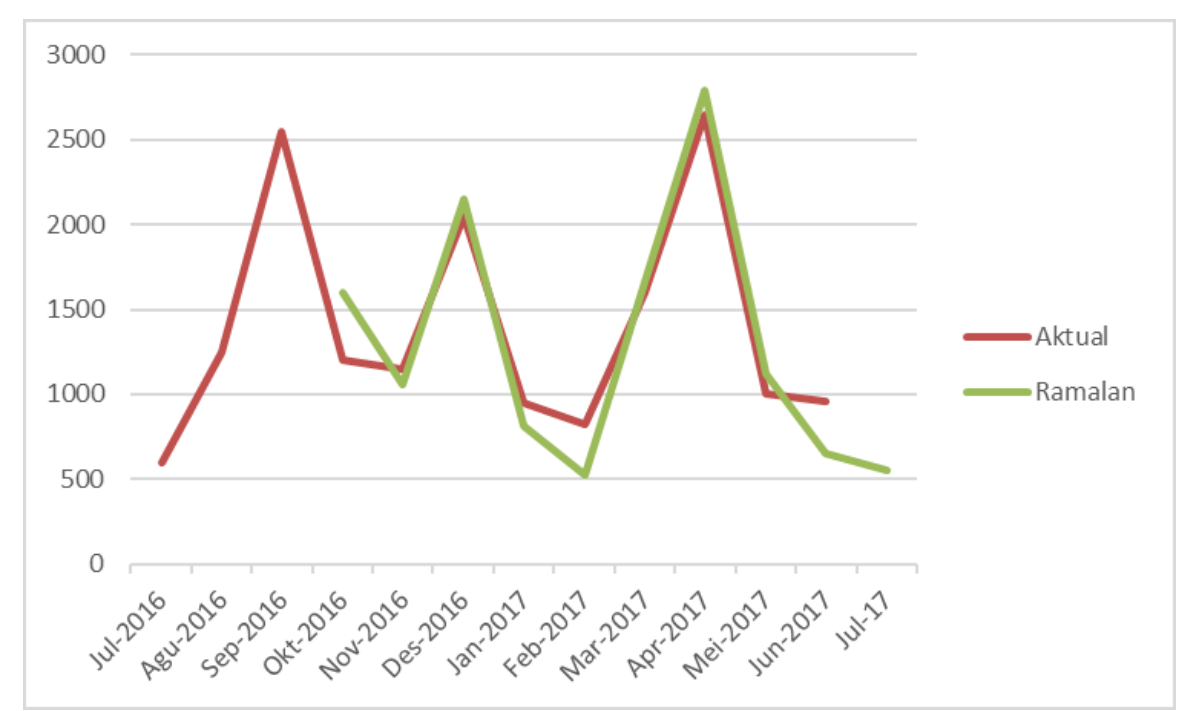

Gambar 4. Grafik Peramalan Metode Winter Exponential Smoothing

3. Perbandingan Hasil Peramalan Metode Holt Double Exponential Smoothing dan Metode Winter Exponential Smoothing

Tabel 3. Perbandingan Hasil Peramalan Metode Holt dan Winter

\begin{tabular}{|l|c|c|c|}
\hline Periode & Data Aktual & $\begin{array}{c}\text { Hasil Peramalan } \\
\text { Holt }\end{array}$ & $\begin{array}{c}\text { Hasil Peramalan } \\
\text { Winter }\end{array}$ \\
\hline Jul-2016 & 600 & & \\
\hline Agu-2016 & 1250 & 1900 & \\
\hline Sep-2016 & 2550 & 3382 & \\
\hline Okt-2016 & 1200 & 1551 & 1602.2 \\
\hline Nov-2016 & 1150 & 952 & 1058 \\
\hline Des-2016 & 2050 & 2079 & 2152.2 \\
\hline Jan-2017 & 950 & 883 & 818.1 \\
\hline Feb-2017 & 820 & 509 & 521.5 \\
\hline Mar-2017 & 1600 & 1582 & 1663.6 \\
\hline Apr-2017 & 2650 & 3149 & 2789.6 \\
\hline Mei-2017 & 1000 & 1111 & 1123.4 \\
\hline Jun-2017 & 960 & 599 & 649 \\
\hline Jul-2017 & & 599 & 549.6 \\
\hline
\end{tabular}


Setelah dilakukan perhitungan peramalan dengan menggunakan kedua metode, maka kemudian dilakukan langkah untuk membandingkan hasil dari masing-masing metode ditinjau dari nilai kesalahan yang paling kecil dan juga perbandingan kedekatan data aktual dan data hasil peramalan. Hasil akhir dari perbandingan kedua metode ini dapat di ketahui dari tabel 3 dan gambar 5. Dari penelitian yang telah dilakukan, dapat diketahui bahwa metode Winter Exponential Smoothing lebih tepat digunakan untuk menyelesaikan studi kasus perhitungan peramalan penjualan souvenir pada UD. Fajar Jaya dengan nilai MAPE sebesar $12.6 \%$.

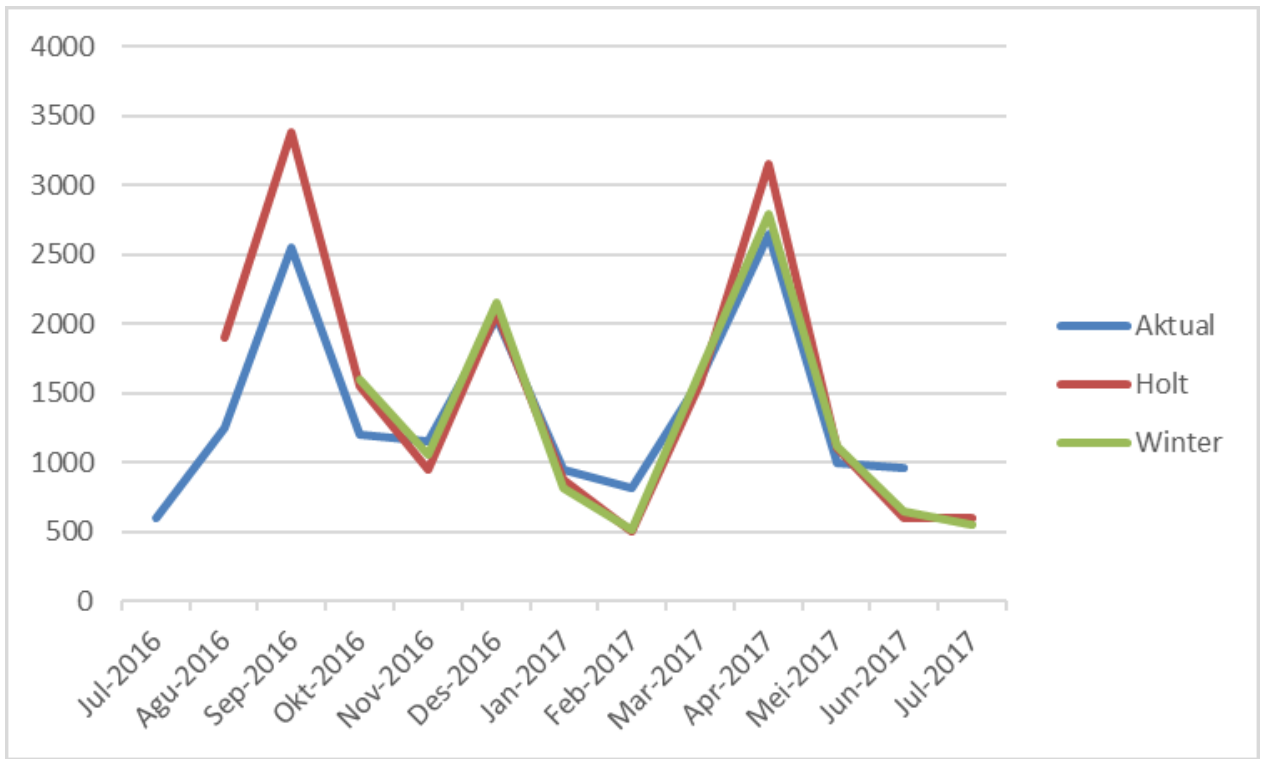

Gambar 5. Grafik Perbandingan Peramalan Metode Holt dan Winter

\section{KESIMPULAN DAN SARAN}

Setelah dilakukan simulasi perkiraan penjualan yang akan datang dengan menggunakan dua metode yaitu metode Holt Double Exponential Smoothing dan metode Winter Exponential Smoothing, diperoleh hasil peramalan untuk metode Holt Double Exponential Smoothing bulan Juli tahun 2017 adalah sebesar 599 item yang mungkin akan terjual dengan tingkat kesalahan peramalan MAPE sebesar $20.5 \%$. Sedangkan untuk peramalan menggunakan metode Winter Exponential Smoothing pada bulan Juli tahun 2017 adalah sebesar 549.6 item yang mungkin akan terjual dengan tingkat kesalahan MAPE sebesar $12.6 \%$. Kesimpulan yang dapat ditarik dari penelitian yang telah dilakukan terhadap data penjualan souvenir pada UD. Fajar Jaya adalah bahwa metode Winter Exponential Smoothing lebih cocok diaplikasikan pada studi kasus penjualan souvenir di UD. Fajar Jaya ini daripada metode Holt Double Exponential Smoothing. Hal ini tidak terlepas dari pola data penjualan yang diperoleh dari trend data periode sebelumnya. Dari trend data yang diperoleh, di ketahui pola data lebih mengarah kepada trend data musiman daripada data linier.

Hasil dari penelitian ini dapat digunakan oleh eksekutif perusahaan untuk membuat perencanaan strategis terkait manajemen stok produk yang dijual, dan penentuan strategi pemasaran tahun-tahun mendatang. Dengan mengaplikasikan metode ini, eksekutif dapat memperkirakan berapa stok produk yang harus d sediakan dalam kurun waktu tertentu.

Saran untuk pengembangan penelitian ini mungkin dapat dilakukan dengan membandingkan metode Winter Exponential Smoothing (Triple Exponential Smoothing Multiplicative) dengan metode Triple Exponential Smoothing Additive, sehingga dapat diketahui metode mana yang paling efektif untuk di aplikasikan pada peramalan dengan pola data musiman.

\section{DAFTAR PUSTAKA}

Agustine, A. (2017). Forecasting Fitness Gym Membership Pada Pusat Kebugaran "The Body Art Fitness, Aerobic \& Pool" Menggunakan Metode Exponential Smoothing. Jurnal Ilmiah Matematika, 3(6), 1-7. 
Andini, TD. \& Auristandi, P. (2016). Peramalan Jumlah Stok Alat Tulis Kantor di UD. Achmad Jaya Menggunakan Metode Double Exponential Smoothing. Jurnal Ilmiah Teknologi Informasi Asia, 10(1), 1-10.

Biri, R. \& Langi, YAR. \& Paendong, MS. (2013). Penggunaan Metode Soothing Exponential dalam Meramal Pergerakan Inflasi Kota Palu. Jurnal Ilmiah Sains 13(1), 68-73.

Hartono, A. (2012). Perbandingan Metode Single Exponential Smoothing dan Metode Exponential Smoothing Adjusted for Trend (Holt's Method) Untuk Meramalkan Penjualan Studi Kasus: Toko Onderdil Mobil Prodi Purwodadi. Jurnal Eksis 5(1), 8-18.

Lieberty, A. \& Imbar, RV. (2015). Sistem Informasi Meramalkan Penjualan Barang Dengan Metode Double Exponential Smoothing (Studi Kasus: PD. Padalarang Jaya).Jurnal Teknik Informatika dan Sistem Informasi (JUTISI) 1(1), 27-32.

Mansyur. \& Rohadi, E. (2015). Sistem Informasi Peramalan Stok Barang di CV. Annora Asia Menggunakan Metode Double Exponential Smoothing. Jurnal Informatika Polinoma 2(1), 45-49.

Mahkya, DA. \& Yasin, H. \& Mukid, MA. (2014). Aplikasi Metode Golden Section Untuk Optimasi Parameter Pada Metode Exponential Smoothing. Jurnal Gaussian 3(4), 605-614.

Supratna, A.\& Susanti, D. \& Hertini, E. (2017). Application of Holt Exponential Smoothing And ARIMA Method For Data Population In West Java. IOP Conf. Series Material Science and Engineering 166, $1-4$.

Siregar, B.\& Butar-Butar, A. \& Rahmat, RF.\& Andayani, U \& Fahmi, F. (2017). Comparison of Exponential Smoothing Methods in Forecasting Palm Oil Real Production. IOP Conf. Series: Journal of Physics Series 801, 1-4.

Utama, CA.\& Watequlis, Y. (2016). Pengembangan SI Stok Barang Dengan Peramalan Menggunakan Metode Double Exponential Smoothing (Studi Kasus : PT. Tomah Jaya Elektrikal). Jurnal Informatika Polinoma 2(4), 147-153. 